\title{
TÖLKE, BENEDIKTA: GRACIAS A MISERICORDIA: EIN RELIGIÖSER SYNKRETISMUS IN DER DOMINIKANISCHEN REPUBLIK. BERLIM: WISSENSCHAFTLICHER VERLAG BERLIN, 2011, 371P.
}

Elaine Padilha Guimarães ${ }^{1}$

A antropóloga e economista alemã Benedikta Tölke realizou o que talvez seja a única etnografia da Santería da República Dominicana disponível até o momento, a qual rendeu-lhe o título de doutora em Etnologia pela Universidade de Göttingen. A pesquisa de campo etnográfica foi realizada entre setembro de 2005 e dezembro de 2006, em diversas áreas do país, com especial concentração na região metropolitana da capital Santo Domingo. A obra revela grande esmero, riqueza de detalhes e uma atitude profundamente respeitosa e até mesmo carinhosa para com seus sujeitos de pesquisa.

A Santería dominicana é uma religião de possessão afro-americana que combina elementos da matriz africana com o Catolicismo e, mais recentemente, com traços da Nova Era. Sincrética por excelência, ela constitui um sistema extremamente flexível e dinâmico. Em seu centro está o culto de divindades sincretizadas com diversos santos católicos denominadas misterios, equivalentes aos orixás do resto do Caribe e do Brasil. Também existe a crença nas almas dos mortos que sobrevivem à morte do corpo e seguem exercendo influência no dia a dia dos vivos. Entre uma e outra categoria, há uma miríade de outras entidades de classificação mais problemática, que formam um vasto panteão.

Dois capítulos inteiros são dedicados à investigação das origens da religião, descortinando um amplo panorama histórico da República Dominicana, o qual apresenta muitos paralelos com o Brasil colonial. A colonização espanhola, iniciada com a chegada de Cristóvão Colombo, em 1492, teve

${ }^{1}$ Licenciada em Filosofia pela Universidade Federal do Rio Grande do Sul (UFRGS), M.A. em Letras, Antropologia Social e Jornalismo pela Universidade de Hamburgo, Alemanha 
como objetivo primordial a exploração do ouro, organizada pelo próprio navegante, e como consequência o rápido extermínio das populações autóctones. Após o ciclo do ouro, é implantada a economia açucareira, tendo como base o braço do escravo africano. Boa parte da ilha passa oficialmente às mãos da coroa francesa, já no fim do séc. XVII. A autora enfatiza os loci sociais nos quais as populações de origem africana puderam reviver e reconfigurar suas práticas religiosas durante o período colonial. Entre eles estão os chamados manieles, o equivalente aos quilombos brasileiros, que existiram em grande número na ilha; a paisagem urbana incipiente, dominada pelos libertos; as irmandades católicas dos negros, que existem até hoje e cujos santos patronos têm um papel central na Santería contemporânea. Tölke afirma que "[...] a formação da estrutura básica do culto tal como o conhecemos hoje já estava concluída no fim do período colonial espanhol" (2011, p. 290).

Boa parte da vívida descrição dos misterios, rituais de possessão, altares, das comidas, consultas divinatórias, dos trabajos, tambores (palos), das festas (fiestas de palo) e floras (botánicas) lembram o Candomblé e o Batuque brasileiros. As demandas dos fiéis incluem tipicamente problemas financeiros, amor e magia direcionada à vingança. Comum a todos os misterios é sua representação por meio de imagens impressas - as cromolitografías. Chama a atenção o fato de a pesquisadora afirmar, literalmente, que os mistérios são associados às cromolitografías em si. Seu ponto de partida para a análise de cada misterio é a complexa iconografia dessas gravuras - por exemplo, de Nossa Senhora das Dores, Santa Ana ou do Arcanjo São Miguel - as quais são cultuadas nos altares e rituais.

Cada divindade é assignada a uma das 21 Divisiones, uma categoria recorrente, cuja extensão é definida pelos adeptos de múltiplas maneiras. A prática religiosa inclui, de fato, apenas algumas poucas Divisiones hierarquicamente concebidas. No topo estão os Radás/Los Blancos, dotados dos atributos claridade e bondade; abaixo deles, os Guedés/Los Negros, presidindo os domínios da morte e possuidores de caráter ambivalente. Num terceiro nível, estão os irascíveis Petrós, de caráter francamente deletério. A possessão por um Petró tem um aspecto bastante intenso, vindo acompanhada de convulsões violentas e atos como a perfuração da pele, ingestão de querosene, 
brasas acesas e cacos de vidro. São eficientíssimos especialistas em provocar o mal. Radás e Petrós também são categorias do Voudou haitiano. A última División é a dos Indios, seres inofensivos, infantis e ligados à água. Um dado para o qual a autora chama atenção é o fato de que faz parte da identidade nacional dominicana a noção de certa raiz indígena, a qual, entretanto, é escassamente corroborada pela historiografia, que aponta para seu extermínio, já nas primeiras décadas do séc. XVI.

A autora constrói um extenso quadro comparativo das divindades yorubá, dominicanas, brasileiras, cubanas, haitianas e trinitárias (2011, p. 300-302), no qual percebe-se, pelo menos no caso das religióes afro do Brasil, pouca familiaridade com a literatura atual. Fixando-se na nomenclatura africana, ela falha em reconhecer a patente correspondência de vários misterios dominicanos com entidades brasileiras. Entre eles estão o Barón del Cementerio/Profeta Elias, líder da División dos Guedés/Negros, cultuado nos cemitérios às segundas-feiras - provavelmente um equivalente de Exu/ Bará. Anaisa PiélSanta Ana corresponde a Oxum, enquanto Belié Belcán/ São Miguel Arcanjo, líder dos Radás, reúne atributos centrais de Xangô.

Mais além das evidentes correspondências entre essas divindades e os orixás brasileiros e de outros países, saltam aos olhos, no que tange à categorização nativa das divindades, semelhanças estruturais entre a Santería dominicana e aquela que é considerada a mais genuinamente brasileira das religiōes - a Umbanda. Poderíamos mencionar aqui, além das quatro Divisiones supracitadas, que se assemelham à classificação das entidades pela Umbanda e Quimbanda em orixás, pretos-velhos, caboclos e exus, também a categoria da Linea: existem a Linea Blanca, a Linea Cruzada, a Africana etc. Há ainda uma estirpe de espíritos de personagens histórico-legendários de características heroicas, como certos caciques indígenas que teriam encabeçado revoltas contra o poder central, o Doctor Gregorio, médico venezuelano ao qual se atribui grande altruísmo e o líder milenarista Papá Libori. Estes últimos têm lugar garantido nos altares do oeste do país. Torna-se patente aí a relação com o Espiritismo, que a autora admite, mas não chega a aprofundar. Há ainda toda uma série de curiosos misterios representados nas cromolitografias, refratários a qualquer categorização apressada: partes santificadas 
do corpo de Deus como La Mano Poderosa e conceitos abstratos como El Gran Poder de Dios e Las Tres Potencias Africanas, esta representada por uma tríade composta pelas efígies de uma beldade branca, um militar negro e um índio. Algumas delas recordam a iconografia das cartas de Tarot. Um dado interessantíssimo é uma possível relação de inversão entre cromolitografía e misterio, em vários casos. Citaremos apenas os exemplos de Lenglesú Taguedól Sagrado Coração de Jesus, cuja representação é o conhecido Cristo de olhos misericordiosos apontando para o próprio coração visível, e Fe, Esperanza y Caridad, representada por três bebês de rostos angelicais. Ambos pertencem à División dos temíveis Petrós, conjurados para provocar abortos, impotência sexual masculina, lesões e mortes por acidentes de trânsito.

Curiosamente, não há uma denominação êmica para esses cultos sincréticos. O termo Santería foi escolhido pela pesquisadora como o mais adequado, pois sublinha o culto aos santos sincretizados com as divindades. A terminologia nativa tampouco contém um termo genérico para os sacerdotes. Outra característica distintiva em relação ao resto das religiões afro-americanas é o fato de os adeptos não só não terem consciência das raízes africanas e, portanto, do caráter sincrético dos cultos que praticam como o de o negarem veementemente. Segundo Tölke (2011), a religião apresenta um caráter "individualista” em todos os seus aspectos: não existe nenhum tipo de organização ou federação central, os sacerdotes agem de maneira completamente independente e autônoma, não existem dogmas e a articulação do saber religioso não se dá de modo esotérico.

A Santería é praticada em todo o país e em todas as camadas socias, de forma especialmente intensa em áreas da região metropolitana de Santo Domingo e em três províncias nas regiôes fronteiriças do Haiti, onde a população negra é maior do que em outras áreas. Dentro das ditas regiōes, porém, a pesquisadora não detecta uma relação de dependência entre cor ou camada social e a probabilidade de alguém ser adepto. Indivíduos das camadas mais baixas tendem a assumir mais frequentemente o pertencimento religioso. A maioria dos adeptos define-se como cristão e não vê contradição nisso. A transição entre práticas católicas e de Santería se dá muitas vezes dentro de um continuum. Por outro lado, o pertencimento a 
ela não faz parte da identidade pública dos indivíduos das camadas sociais superiores - jamais ver-se-ão políticos batendo cabeça para os santos diante de jornalistas em épocas de eleição.

Para a autora (2001), essa situação relaciona-se à ampla negação das origens africanas pelos próprios adeptos, entranhando-se na própria identidade dominicana. Como em outros países da América hispânica, também aí a herança espanhola - personificada pela elite majoritariamente branca do país - é sublinhada em detrimento de outras influências socioculturais ${ }^{2}$. Há uma enorme carga de preconceitos em relação àquilo que é considerado africano, o que guarda relação, segundo a autora (2001), com a imagem extremamente negativa dos haitianos com os quais certa qualidade "negra/ africana” é associada. A pervasiva xenofobia contra eles rendeu o famigerado Masacre del Perejil, durante a ditadura Trujillo, episódio imortalizado em um romance de Mario Vargas Llosa (2001, p. 186-195). A maioria dos haitianos vive em condiçôes de extrema marginalidade e isolamento. Talvez possa-se afirmar que o haitiano estrangeiro é o duplo negativo do cidadão dominicano. Ademais, a imagem daqueles contém um elemento altamente ambivalente: eles são reconhecidos (e temidos) como profundos conhecedores de magia negra.

Sob o ponto de vista teórico, o trabalho distancia-se programaticamente dos Estudos da Diáspora Africana, para alinhar-se ao campo de Estudos sobre Sincretismo. Tölke (2011) realiza um apanhado geral das concepções teóricas do sincretismo, de Herskovits até Stewart e Shaw. Estes definem os chamados antissincretismos por oposição aos sistemas de crenças abertamente sincréticos. Tölke (2011) classifica a Santería dominicana entre estes últimos. Ademais a autora recorre à Teoria da Integração Conceitual (conceptual blending) de Fauconnier e Turner, (2003) que faz parte do espectro das teorias cognitivas da Linguística, bem como à Teoria da Praxis de Greenfield e Droogers, (2001) como modelos de explicação de processos sincréticos. De acordo com Benedita Tölke (2011), a ação e a apreensão são

2 Sobre a "introjeção no negro e no mulato dos valores discriminatórios do branco" no Caribe, a avaliação de Darcy Ribeiro (1983, p. 357) parece aplicar-se bastante bem ao caso da República Dominicana. 
influenciadas por estruturas simbólicas. Tais estruturas simbólicas fornecem repertórios mutáveis de significados, os quais são acessados pelos indivíduos para explicar a realidade, ao mesmo tempo em que as vão modificando. Neste processo, segundo Tölke (2011), foram privilegiados elementos comuns às religiōes da África Ocidental e Central e ao Catolicismo popular europeu, no qual as práticas mágicas não eram (e não são) incomuns. Este enfoque implica um conceito dinâmico de cultura e uma visão do símbolo como uma resultante da ativação de esquemas da experiência.

Um problema que a etnografia de Tölke (2011) enfrenta, por causa de sua própria concepção - a etnografia da religião de todo um país - é o da circunscrição do que pertence ao corpus de práticas religiosas da Santería e do que não pertence e são práticas religiosas populares de variadas matrizes. No final, muitas delas poderiam pertencer ou não à Santería. A falta de um termo êmico genérico para a religião é um dado altamente significativo no que tange a isso. Talvez não caiba falar, no presente estado da investigação, de uma única religião, mas antes de um universo de crenças e práticas que guardam correlações ora mais ora menos estreitas entre si. Faltaria simplesmente haver dito que ainda é muito cedo para colar a etiqueta de religião $X$ sobre todas essas práticas.

No último capítulo, a autora (2011) procura apontar para tendências da Santería contemporânea para o futuro, as quais caberia acompanhar e analisar mais profundamente: seu papel na vida dos homossexuais, outro grupo bastante discriminado no interior da sociedade; o influxo de elementos do Voudou haitiano, orientais e do espectro Nova Era, bem como sua crescente transnacionalização, devido a processos migratórios. A obra revela, na verdade, um sem-número de aspectos da religião que constituiriam por si só objetos de pesquisa dignos de uma investigação in loco. Dentro do tema dos fluxos transnacionais, há o caso das curiosas cromolitografias, com suas iconografias à primeira vista incongruentes e heteróclitas, que são importadas de lugares como México, Venezuela, Estados Unidos e China. Outro tema suscitado pela leitura de Gracias a misericordia (2011) relaciona-se à comparação entre a Santería dominicana e o Candomblé, a Umbanda, a Quimbanda e o Espiritismo brasileiros. Resta-nos esperar por 
uma necessária tradução desta obra pioneira a um idioma mais acessível à comunidade dos antropólogos que se dedicam aos fenômenos religiosos afro e latino-americanos em geral.

\section{REFERENNCIAS}

FAUCONNIER, Gilles; TURNER, Mark. The way we think: conceptual blending and the mind's hidden complexities. New York: Basic Books, 2003. GREENFIELD, Sidney M.; DROOGERS, André. Recovering and Reconstructing Syncretism. In: Ibid. Reinventing Religions: Syncretism and Transformation in Africa and the Americas. Oxford: Rowman \& Littlefield Publishers, p. 21-42, 2001.

RIBEIRO, Darcy. As Américas e a Civilização. Formação Histórica e Causas do Desenvolvimento Desigual dos Povos Americanos. Petrópolis: Vozes, 1983. TÖLKE, Benedikta. Gracias a Misericordia: Ein religiöser Synkretismus in der Dominikanischen Republik. Berlim: Wissenschaftlicher Verlag Berlin, 2011 .

VARGAS LLOSA, Mario. A festa do Bode. São Paulo: Mandarim, 2001. 